\title{
EL TRIBUNAL EUROPEO DE DERECHOS HUMANOS, EL TRIBUNAL DE JUSTICIA DE LA UE Y «LE MOUVEMENT NÉCESSAIRE DES CHOSES»
}

\author{
LUIS LÓPEZ GUERRA \\ Catedrático de Derecho Constitucional \\ Universidad Carlos III de Madrid \\ Juez del Tribunal Europeo de Derechos Humanos
}

\begin{abstract}
SUMARIO
I. Introducción. II. El ámbito de la jurisdicción del TEDH frente a las instituciones de la Unión: Senator Lines. III. La jurisdicción del TEDH frente a la ejecución por los Estados del Derecho de la Unión: Bosphorus, Michaud, Avotins. IV. TEDH y cuestión prejudicial. Ullens de Schooten. V. El ámbito de la jurisdicción del TJUE. Akerberg Fransson. VI. El diálogo entre Tribunales. VII. El TEDH y la jurisprudencia del Tribunal de Justicia. $A$ y $B$ contra Noruega, Tarakbel, X contra Letonia.
\end{abstract}

\section{INTRODUCCIÓN}

La existencia de dos sistemas de protección, a nivel europeo, de los derechos básicos de la persona (derechos fundamentales en la terminología de la Carta de Derechos Fundamentales de la Unión Europea, derechos humanos en la del Convenio Europeo) no ha dejado de plantear cuestiones referidas a su interrelación y la de los órganos que los integran. Para un análisis inicial de esta interrelación es útil tener en cuenta las peculiares características relevantes de cada uno de esos sistemas.

Por lo que se refiere al Convenio Europeo de Derechos Humanos de 1950, es bien sabido que su ámbito geográfico es considerablemente más extenso que el de la Unión Europea, comprendiendo cuarenta y siete países, de los que (hoy) sólo 28 son miembros de la Unión. Pero su característica definitoria es el ámbito determinado de su objeto material, esto es, exclusivamente la protección de los derechos reconocidos en el texto del Convenio y sus protocolos. Objeto que se ha mantenido, desde la entrada en vigor del Convenio, todo a lo largo de la historia 
del sistema, sujeto sólo a cambios en su contenido concreto (el elenco de derechos protegidos, ampliado mediante diversos protocolos) y las vías procesales para su actuación.

Otra es la situación del sistema de protección de derechos de la Unión Europea. Aparte de su distinta extensión geográfica, ese sistema viene a integrarse en un marco jurídico mucho más amplio, que tiene por objeto materias de muy distinta índole (sociales, económicas, de relación exterior) y que pretende constituirse como un ordenamiento jurídico autónomo, y no como un mero resultado de acuerdos interestatales. La ordenación relativa al reconocimiento y defensa de derechos fundamentales aparece así como un sector parcial (subsistema) dentro de ese ordenamiento, y, en consecuencia, estrechamente relacionado con los objetivos y principios básicos que a éste inspiran.

Ahora bien, este sistema muestra una nota distintiva adicional. No representa - como sí es el caso con el Convenio Europeo- una ordenación concebida desde un principio con el fin de proteger una lista detallada de derechos, y que haya mantenido permanentemente ese objeto. Por el contrario, es un tema clásico en cualquier descripción del mecanismo de garantía de derechos en la Unión Europea la evolución de ese mecanismo y su desarrollo paulatino, primeramente en una fase pretoriana, a partir de las sentencias Stauder e Internationale Handelsgessellschaft, y posteriormente a través de progresivas referencias a los derechos humanos en los textos normativos ${ }^{1}$, referencias formalizadas finalmente en el reconocimiento por el Tratado de la Unión Europea en 2009 de la fuerza vinculante de la Carta de Derechos Fundamentales. En otras palabras, hasta fechas relativamente recientes, el sistema de la Unión Europea de protección de derechos fundamentales aparecía como un añadido o complemento de la protección ofrecida por el Convenio y el Tribunal Europeo de Derechos Humanos.

Obviamente, esta situación ha cambiado a partir del Tratado de Lisboa. El sistema propio de protección de derechos tiene ya una base normativa específica, y, lo que es aún más relevante, el órgano jurisdiccional clave del sistema, el Tribunal de Justicia de la Unión Europea, ha pasado a configurarse formalmente como el instrumento superior de defensa de los derechos reconocidos en la Carta. Lo que viene a dar lugar a una dualidad de tribunales competentes sobre las mismas materias y en el mismo ámbito geográfico: en las mismas materias porque el contenido de la Carta incluye el del Convenio de 1950; en el mismo ámbito

1 En cuanto a la primero, el Preámbulo al Acta Única Europea, adoptada el 27 de enero de 1986, viene a proclamar el respeto de la Comunidad Europea a los derechos fundamentales, tal como derivan de las tradiciones constitucionales comunes, de la Carta Social Europea y del Convenio Europeo de Derechos Humanos. El Tratado de la Unión Europea formado en Maastricht en 1992 ya incluye la referencia al Convenio Europeo en su articulado: en el párrafo segundo del artículo 6 proclama que «la UE respetará los derechos fundamentales tal y como se garantizan en el Convenio Europeo para la protección de los Derechos Humanos y de las libertades fundamentales firmado en Roma el 4 de noviembre de 1950 y tal y como resultan de las tradiciones constitucionales comunes a los Estados miembros como principios generales del Derecho Comunitario». 
porque todos los países miembros de la Unión son también firmantes del Convenio Europeo.

Esa dualidad no implica una diferencia de objetivos, ya que ambos sistemas se inspiran explícitamente en los mismos principios: la Carta de Derechos Fundamentales, en su Preámbulo cita textualmente, como fuente de inspiración, el Convenio Europeo de Derechos Humanos y la jurisprudencia del Tribunal Europeo $^{2}$. Pero sí implica que en una misma materia van a existir dos tribunales con pretensión de actuar como última instancia, sin que pueda hablarse de una relación jerárquica entre ellos, pues ciertamente, la inspiración en el Convenio Europeo de Derechos Humanos a que se refiere la Carta no implica que el Tribunal de Luxemburgo esté sometido al Convenio Europeo de Derechos Humanos ${ }^{3}$ ni a la jurisprudencia del Tribunal de Estrasburgo.

No han faltado voces, a partir de la aprobación del Tratado de Lisboa, que se hayan pronunciado por la creación de mecanismos de coordinación entre ambos tribunales, ante los peligros que supondría la aparición de divergencias entre ellos en la interpretación del contenido y extensión de los derechos reconocidos tanto en la Carta como en el Convenio ${ }^{4}$ : peligros que podrían centrarse en dos aspectos. Por un lado, en la incertidumbre jurídica en que colocarían a ciudadanos y poderes públicos (especialmente órganos judiciales) de los Estados miembros de ambos sistemas en cuanto al sentido de mandatos referentes a aspectos esenciales para el status jurídico de las personas. Pero además, porque tales divergencias se referirían precisamente a derechos que se definen como connaturales a

2 «La presente Carta reafirma, respetando las competencias y misiones de la Comunidad y de la Unión, así como el principio de subsidiariedad, los derechos reconocidos especialmente por las tradiciones constitucionales y las obligaciones internacionales comunes de los Estados miembros, el Tratado de la Unión Europea y los Tratados comunitarios, el Convenio Europeo para la Protección de los Derechos Humanos y de las Libertades Fundamentales, las Cartas Sociales adoptadas por la Comunidad y por el Consejo de Europa, así como por la jurisprudencia del Tribunal de Justicia de las Comunidades Europeas y del Tribunal Europeo de Derechos Humanos».

3 Ver por ejemplo la sentencia Akerberg Fransson (C-617/10, de 26 de febrero de 2013, § 44): Por lo que se refiere, en primer lugar, a las consecuencias que debe deducir un juez nacional en caso de conflicto entre el Derecho nacional y el CEDH, debe recordarse que, si bien los derechos fundamentales reconocidos por el CEDH forman parte del Derecho de la Unión como principios generales — como confirma el artículo 6 TUE, apartado 3-, y el artículo 52, apartado 3, de la Carta exige dar a los derechos contenidos en ella que correspondan a derechos garantizados por el CEDH el mismo sentido y alcance que les confiere dicho Convenio, éste no constituye, dado que la Unión no se ha adberido a él, un instrumento jurídico integrado formalmente en el ordenamiento jurídico de la Unión. En consecuencia, el Derecho de la Unión no regula la relación entre el CEDH y los ordenamientos jurídicos de los Estados miembros y no establece tampoco las consecuencias que debe deducir un juez nacional en caso de conflicto entre los derechos que garantiza dicho Convenio y una norma de Derecho nacional (véase, en este sentido, la sentencia de 24 de abril de 2012, Kamberaj, C-571/10, apartado 62). Para una opinión crítica de esta posición, ver Bruno DE WITTE, «The use of the ECHR and Convention case law by the European Court of Justice» en Patricia POPELIER et. al. (dirs.), Human rights protection in the European legal order: The interaction between the European and the national courts, Intersentia, Cambridge, 2011, pp. 17-34.

4 Así, en fecha temprana, las consideraciones de la Juez del Tribunal Europeo Françoise Tulkens, Les aspects institutionels de l'adhesion de l'Union Européenne à la Convention européenne de sauvergarde des droits de l'homme et des libertés fondamentales, Sesión informativa del 18 de Marzo de 2010 ante la Comisión de Asuntos Constitucionales del Parlamento Europeo. 
la persona y cuya defensa se considera como la misma justificación, en último término, del orden político y jurídico. No sería sólo pues, la seguridad jurídica, sino la mima legitimidad de ese orden lo que se vería amenazada si unos mismos derechos, en principio de valor universal, se vieran definidos e interpretados en forma diversa o contradictoria.

Frente a estas negativas posibilidades, parecen abrirse dos tipos de soluciones. Una de ellas — llamémosla «coordinación formal» sería la recogida evidentemente en el artículo 6.2 del Tratado de la Unión Europea, que prevé que «La Unión se adberirá al Convenio Europeo para la Protección de los Derechos Humanos y de las Libertades Fundamentales. Esta adhesión no modificará las competencias de la Unión que se definen en los Tratados» ${ }^{5}$. Pero esta adhesión no se ha producido, ni, a la vista de la bien conocida Opinión 2/2013 del Tribunal de Luxemburgo parece que vaya a producirse en un futuro próximo. Lo que obliga a tener en cuenta la segunda solución, esto es, la coordinación informal, basada en la convergencia práctica de la jurisprudencia de ambos Tribunales, derivada de la identidad de los principios que rigen ambos sistemas, del proclamado carácter universal de los derechos (denominados como fundamentales o humanos) que en ellos se garantizan, del diálogo entre ambas instancias ${ }^{6}$, y en último término de lo que Montesquieu denominó "le mouvement necéssaire des choses» en el Capítulo 6 del libro XI de Del Espíritu de las Leyes. Como ser verá, y a la luz de las líneas que siguen, tal parece haber sido la vía seguida hasta el momento.

\section{EL ÁMBITO DE LA JURISDICCIÓN DEL TEDH FRENTE A LAS INSTITUCIONES DE LA UNIÓN: SENATOR LINES}

Para un análisis de la situación respectiva de los Tribunales de Estrasburgo y Luxemburgo, puede ser útil tener en cuenta un aspecto a que se hizo referencia más arriba: es decir al hecho de que la actuación del Tribunal de Luxemburgo en materia de derechos fundamentales se va a ir produciendo en forma paulatina en un área sobre la que ya anteriormente el Tribunal de Estrasburgo venía ejerciendo sus competencias. En efecto, y como no podía ser de otra manera, el proceso de

5 Para una exposición sobre los antecedentes del artículo 6.2 del Tratado de la Unión Europea, ver, S. Leutheuser-SchnarRenberger, «Der Beitritt der EU zur EMRK: Eine schier unendliche Geschichte» en C. Hohmann-Dennhart, P. Masuch, M. Villiger (Hrsg.) Grundrechte und Solidarität. Festchrift für Renate JAEGER, Engel Verlag, Kehl, 2010, pp. 135-146; para las vicisitudes del proceso de adhesión de la Unión Europea al Convenio Europeo de Derechos Humanos, entre la abundante literatura, ver D. EngEL, Der Beitritt der Europäische Union zur EMRK, Mohr Siebeck, Tübingen, 2015 .

6 Diálogo no sólo a través de sus sentencias (de lo que se tratará más abajo) sino también a través de reuniones informales de estudio y discusión. La última a la que tuvo el privilegio de asistir el autor de estas líneas se celebró en Luxemburgo el 3 de marzo de 2016, con ponencias de los jueces Malenovsky, Bay Larsen y Jurimäe del Tribunal de Justicia, y Potocki, Bianku y Karakas, del Tribunal Europeo de Derechos Humanos. El autor quiere aquí reconocer su deuda por las ideas recibidas en el curso de esta sesión. 
integración europeo y la actividad de sus órganos no dejaba de afectar en muchos casos a los derechos garantizados por el Convenio Europeo: con la particularidad de que la Comunidad (más tarde Unión) Europea no era parte firmante del Convenio ni por lo tanto sujeta a las obligaciones allí fijadas. Y sin embargo sus actuaciones se producían dentro de la jurisdicción de países que sí eran firmantes del mismo, y daban lugar a demandas ante el Tribunal de Estrasburgo exigiendo el cumplimiento de aquellas obligaciones. Por lo que este Tribunal hubo de enfrentarse con este tipo de demandas, y señalar hasta dónde llegaban sus competencias en relación con materias en el ámbito de la Comunidad Europea.

En un análisis de cómo el Tribunal de Estrasburgo ha definido esas competencias, con ocasión de haberse denunciado ante él vulneraciones de derechos del Convenio derivadas de actuaciones de la Unión Europea, pueden distinguirse inicialmente dos situaciones distintas, según se trate de vulneraciones del Convenio atribuidas a las instituciones propias de la Unión, o bien de vulneraciones derivadas de la actuación de los Estados en ejecución del Derecho de la Unión.

Consideremos el primer supuesto, que no implica excesiva dificultad. Cabe que la vulneración de un derecho reconocido en Convenio se predique de un acto de alguna de las instituciones propias de la Unión como la Comisión, o el Consejo Europeo. Hasta el momento, y al no ser la Unión parte firmante del Convenio, no cabe dirigir directamente demandas frente a ella, por actos de sus órganos. En jurisprudencia bien establecida del Tribunal de Estrasburgo, desde la decisión de la Comisión Europea de Derechos Humanos en el caso CFDT $T^{7}$, en 1978, este tipo de demandas son inadmisibles ratione personae, esto es, por no ser el demandado (Unión Europea) parte firmante del Convenio.

Hay que señalar que, para eludir este obstáculo, en ocasiones los demandantes se han dirigido al Tribunal de Estrasburgo alegando vulneraciones de sus derechos fundamentales por actos de las instituciones de la Unión mediante la vía indirecta consistente en dirigir la demanda conjuntamente frente a todos los Estados miembros de la Unión (que son todos ellos firmantes del Convenio) como corresponsables de los actos de ésta. Tal fue el caso de la demanda presentada por la compañía Senator Lines contra los entonces quince Estados miembros de la Unión. La empresa demandante se quejaba de que la Comisión Europea le había impuesto una elevada multa por vulneración de las reglas de la competencia; y de que, recurrida tal multa ante el Tribunal de Primera Instancia de la Unión Europea, éste había rechazado su petición de suspensión de la ejecución de la multa en tanto se dictaba sentencia definitiva. Ello conduciría a la liquidación de la sociedad, y supondría una vulneración del derecho a un proceso equitativo, de acuerdo con el artículo 6.1 del Convenio.

7 CFDT contra las Comunidades Europeas, decisión de la Comisión Europea de Derechos Humanos de 10 de julio de 1978. 
El Tribunal de Estrasburgo admitió la demanda (lo que no dejó de ser objeto de críticas) frente a los quince Estados, e incluso fijó fecha para la vista oral del caso. No obstante, éste fue cerrado sin decisión final sobre el fondo por parte del Tribunal. La razón fue que, antes de celebrarse la vista ante el Tribunal de Estrasburgo, el Tribunal de Primera Instancia de la Unión anuló la multa impuesta por la Comisión. Como consecuencia, de acuerdo con la apreciación del Tribunal de Estrasburgo, la sociedad demandante dejó de ser víctima de una vulneración de sus derechos y por ello, el Tribunal por una decisión de 10 de marzo de 2004, declaró la demanda inadmisible.

\section{LA JURISDICCIÓN DEL TEDH FRENTE A LA EJECUCIÓN POR LOS ESTADOS DEL DERECHO DE LA UNIÓN: BOSPHORUS, MICHAUD, AVOTINS}

La cuestión es distinta, y aquí si nos encontramos con serias dificultades, en lo que se refiere al sector más amplio del Derecho europeo: es decir, aquellas actuaciones de la Unión Europea que son llevadas a cabo, no por los órganos propios de ésta, sino por los Estados miembros. Como es bien sabido, la Unión dispone de una reducida estructura organizativa; la gran mayoría de las disposiciones de Derecho europeo son ejecutadas o llevadas a la práctica por los poderes legislativos, ejecutivos o judiciales de los Estados miembros. En este sentido, los poderes ejecutivos de los Estados miembros son poderes ejecutivos de la Unión, y lo mismo puede decirse de sus Parlamentos y de sus Tribunales, que se convierten respectivamente en legisladores y en jueces de la Unión.

Ello ha planteado no pocas cuestiones hasta el momento, en lo que se refiere a la protección de derechos fundamentales. ¿Qué ocurre si se alega ante el Tribunal de Estrasburgo que una autoridad de un Estado ha vulnerado un derecho fundamental aplicando un mandato de la Unión Europea? ${ }^{8}$ ¿Cómo puede el Tribunal de Estrasburgo pronunciarse sobre este tipo de casos sin que ello suponga emitir un juicio, no sólo sobre la actuación del Estado, sino también sobre la actuación de la Unión Europea, como última causante de la vulneración alegada? Y ello a pesar de que la Unión como tal no es miembro del Convenio, ni por tanto esté sometida a la jurisdicción del Tribunal.

No han faltado casos en que estos supuestos se han planteado, y contamos ya con una amplia jurisprudencia del Tribunal al respecto. Podemos distinguir entre varias situaciones. En muchos supuestos, el Derecho de la Unión Europea consiste en disposiciones lo suficientemente amplias como para dejar a los Estados miembros un amplio margen de discreción en su aplicación: el Derecho de la

8 Incluso, valga señalar, un mandato del Derecho primario de la Unión; téngase por ejemplo en cuenta el caso Matthews contra Reino Unido, de 18 de febrero de 1999. 
Unión establece una obligación de resultado, y deja al Estado emplear para ello los medios que estime oportunos. Tal sería el bien conocido caso de las directivas de la Unión, que han de ser traspuestas al ordenamiento interno por normas estatales.

En estos casos, cuando se ha alegado ante el Tribunal de Estrasburgo que la ejecución de una directiva europea había producido una vulneración de derechos fundamentales reconocidos en el Convenio, el Tribunal ha procedido a juzgar la norma estatal, y no la norma europea: lo que el Tribunal examina es si, dentro de las posibles alternativas existentes para la ejecución interna del Derecho europeo, el Estado ha escogido una que sea compatible con los mandatos del Convenio. No es el Derecho europeo el objeto del juicio del Tribunal, sino la forma en que el Estado miembro lo ha ejecutado. Tal fue la línea seguida, por ejemplo, por el Tribunal en su sentencia Cantoni contra Francia ${ }^{9}$, referente a la ejecución por este país de una directiva europea que versaba sobre la restricción de la venta de ciertos productos fuera de las farmacias, o en la sentencia Procola contra Luxemburgo ${ }^{10}$, referente a cuotas lecheras. En estos supuestos, pues, el Tribunal no necesitó pronunciarse sobre normas o actos de la Unión, sino sobre la conducta de Estados miembros.

La cuestión ha sido, y sigue siendo distinta cuando la vulneración que se imputa al Estado miembro de la Unión por la ejecución de un mandato de ésta se produce en supuestos en que el Estado no tiene ningún margen de apreciación: es decir, cuando el Estado, al ejecutar un mandato de la Unión Europea no tiene sino una sola línea posible de actuación, y esta línea conduce, según las alegaciones del afectado y recurrente ante Estrasburgo, a una vulneración de los derechos reconocidos en el Convenio. El Estado en cuestión está sujeto al respeto de esos derechos, independientemente de su pertenencia a la Unión Europea, o a otra organización supra- o internacional y debe abstenerse de violarlos; pero al tiempo, y como miembro de la Unión Europea, debe ejecutar los mandatos de ésta. En estos supuestos, al juzgar al Estado, el Tribunal debe forzosamente pronunciarse también sobre el mandato de la Unión que determina la actividad del Estado. En estos casos, un pronunciamiento del Tribunal sobre la actuación de la Unión parecería inevitable, pese a que la Unión no es, aún, parte firmante del Convenio.

Tal fue la situación que se planteó en el caso Bosphorus contra Irlanda ${ }^{11}$. En aplicación de acuerdos adoptados por las Naciones Unidas, el Consejo Europeo acordó la inmovilización de un avión integrado en una compañía de aviación serbia; el gobierno de Irlanda fue el encargado de llevar a cabo esta inmovilización. La compañía propietaria, tras producirse un fallo del Tribunal de Luxemburgo

9 Cantoni contra Francia, de 15 de noviembre de 1996

10 Procola contra Luxemburgo, de 28 de septiembre de 1995.

11 Bosphorus Hava Yollari Turizm ve Ticaret Anonim Sirketi contra Irlanda, de 30 de junio de 2005 (Gran Sala). 
reconociendo la legalidad de la medida, acudió al Tribunal de Estrasburgo, aduciendo que el gobierno irlandés vulneraba derechos fundamentales. Pero la decisión del gobierno irlandés derivaba directamente de un mandato europeo; juzgar esa decisión era forzosamente emitir también un juicio sobre un mandato de la Unión.

El Tribunal, en su sentencia en Bosphorus resolvió el caso señalando que el ordenamiento de la Unión Europea, tanto por sus disposiciones y mandatos materiales, como por la existencia de una organización procesal, ofrecía una garantía de los derechos fundamentales equivalente a la ofrecida por el Convenio; por ello, los actos de la Unión disfrutarían de lo que se ha denominado una presunción de convencionalidad $^{12}$. En principio, esos actos debían considerarse como estando de acuerdo con el sistema de derechos fundamentales del Convenio, y por ello, el Tribunal de Estrasburgo no consideraba pertinente el llevar a cabo un nuevo examen. Ahora bien, tal posición no suponía la existencia de una presunción iuris et de iure, sino sólo iuris tantum: si el Tribunal, caso por caso, apreciaba un nivel insuficiente de protección por parte de la Unión, podría proceder a examinar las demandas que se plantearan frente a actuaciones estatales en ejecución del Derecho europeo.

Esta doctrina, conocida como doctrina Bosphorus ha sido consistentemente aplicada por el Tribunal desde el año 2005 (por ejemplo en la decisión Cooperatieve Producentenorganisatie ${ }^{13}$, en 2009). Esta doctrina ha impedido que el Tribunal se pronuncie, en forma indirecta, sobre actuaciones de la Unión en cuanto entidad que no es parte del Convenio.

La aprobación del Tratado de Lisboa, y la atribución de fuerza vinculante a la Carta de Derechos Fundamentales de la Unión ha venido a reforzar, por el momento (y en tanto se produzca una eventual adhesión de la Unión al Convenio Europeo de Derechos Humanos) la aplicación de la doctrina Bosphorus. Sus principios generales se han visto, por decirlo así, codificados en la Sentencia Michaud c. Francia ${ }^{14}$, que, si bien considera no aplicable al caso la doctrina, viene a sistematizar sus principios básicos. La cuestión planteada se refería a la ejecución por Francia de la Directiva 2005/ 60 /CE de 26 de octubre de 2005, ejecución que, según el recurrente, habría vulnerado su derecho a la privacidad del artículo 8 del Convenio $^{15}$. El Tribunal se plantea la posibilidad de la aplicación de la doctrina Bosphorus al caso, teniendo en cuenta el reforzamiento de la garantía de derechos

12 GARliCKI, L., «Cooperation of Courts: the Role of Supranational Jurisdictions in Europe» en International Journal of Constitutional Law, vol. 6 (2008) pp. 509-530, p. 527.

13 Cooperatieve Producentenorganisatie van de Nederlandse kokkelvisserij u.a. contra Paises Bajos (decisión), de 20 de enero de 2009.

14 Michaud contra Francia, de 6 de diciembre de 2012.

15 Ver, entre los múltiples comentarios a este caso, Ch. Hartman, D. Grisay, «Arrêt Michaud: la Cour européenne des droits de l'homme comme bouée de sauvetage de la protection des droits fondamentaux dans l'Union européenne?», ULMB, Revue de jurisprudence de Liège, Mons et Bruxelles, 13/2013, pp. 733-743. 
fundamentales que ha supuesto la mencionada entrada en vigor de la carta de Derechos Fundamentales. E insiste en los principios de Bosphorus: los Estados firmantes del Convenio están vinculados por sus mandatos también cuando ejecutan obligaciones derivadas de su pertenencia a una organización internacional a la que hayan trasferido parte de su soberanía. El Tribunal estima también que, en principio, tales medidas de ejecución pueden presumirse compatibles con el Convenio cuando la organización internacional en cuestión concede a los derechos fundamentales (material y formalmente) una protección equivalente a la prestada por el Convenio, y se han puesto en marcha los mecanismos necesarios para la garantía de esos derechos, con especial atención a la función del Tribunal de Justicia. Se establece así, en esos supuestos, una presunción de convencionalidad, que sólo podrá verse desvirtuada en caso de manifiesta desprotección del derecho en cuestión.

Pero el Tribunal subraya dos matices de relevancia. En primer lugar, esa presunción no es aplicable si, en el caso de la Unión Europea, el Estado dispone de una margen de discrecionalidad en la ejecución de esas obligaciones (por ejemplo, en la transposición de una directiva). Además tampoco es aplicable si, en opinión del Tribunal, las garantías existentes en el seno de la organización internacional presentan en el caso una insuficiencia manifiesta para asegurar el derecho fundamental en cuestión.

En Michaud el Tribunal, pese a la vigencia de la Carta de Derechos Fundamentales, no aplica, a la vista de esos matices, la presunción Bosphorus. Por un lado, considera que Francia disponía de un margen de apreciación en la aplicación de la directiva europea, por lo que no estaba sometido a una obligación ineludible de llevar a cabo su actuación en al forma en que lo hizo. Por ello, el Tribunal estima que debe examinar si la forma en que Francia aplicó el mandato europeo es compatible con el Convenio. La doctrina Bosphorus no confiere pues en estos supuestos, una presunción inicial de convencionalidad.

Por otra parte, como otra razón para no aplicar esa doctrina, el Tribunal no acepta que la actuación de los mecanismos de protección procesal proporcionados en el caso por el Derecho de la Unión fuera equivalente a la exigida por el Convenio. Pues, si bien el Consejo de Estado podría haber planteado al Tribunal de Justicia una cuestión prejudicial referente a la interpretación de la directiva (como sí lo había hecho en un caso anterior, en relación con el derecho a un juicio justo) no había procedido así en el caso, con lo que los mecanismos de protección procesal previstos en el Derecho de la Unión no se habían aplicado. En consecuencia, y también por este motivo, el Tribunal rehúsa aplicar la presunción Bosphorus y entra a analizar en el fondo la actuación del Estado francés, en su ejecución de la Directiva europea, a la luz del artículo 8 del Convenio. Debe señalarse, en todo caso, que, en su examen de fondo, el Tribunal concluye que no ha habido vulneración de ese artículo.

Esta concreción de la doctrina Bosphorus implica que uno de los factores para otorgar una presunción de convencionalidad a las actuaciones de los Estados en 
ejecución de las obligaciones derivadas de su pertenencia a la Unión Europea es la protección que supone la intervención del Tribunal de Justicia. Esto, como se verá más abajo, trae como consecuencia la necesidad de una coordinación entre las posiciones de los dos Tribunales en lo que se refiere a la pertinencia y régimen de la cuestión prejudicial.

Las líneas expresadas en Bosphorus y Michaud han sido precisadas en una ocasión posterior en la sentencia del TEDH en el caso Avotins ${ }^{16}$ en que el Tribunal insiste en sus argumentos:

$\S 105$. El Tribunal reitera que la aplicación de la presunción de protección equivalente en el sistema jurídico de la Unión Europea está sujeta a dos condiciones, establecidas en la sentencia Michaud arriba citada. Estas son la ausencia de todo margen de maniobra por parte de las autoridades nacionales, y la puesta en práctica de todo el potencial de los mecanismos de supervisión proporcionados por el Derecho de la Unión (...). El Tribunal debe por tanto verificar si tales condiciones se vieron satisfechas en el presente caso».

Iniciando su análisis de las condiciones previas a la posible aplicación de la presunción de convencionalidad, el Tribunal efectúa algunas precisiones. En lo que se refiere al primer aspecto, esto es, la discrecionalidad del Estado en la aplicación del Derecho de la Unión, el Tribunal tiene en cuenta que la norma de ese Derecho que creaba obligaciones al Estado demandado era un reglamento (el Reglamento de Bruselas I) y no, como en el caso Michaud, una directiva, que dejaba un amplio margen de actuación a las autoridades nacionales.

En cuanto a la segunda condición, esto es, si se habían puesto en práctica en el caso los mecanismos proporcionados por el Derecho de la Unión para garantizar el derecho invocado por el recurrente, el Tribunal añade nuevas consideraciones a la doctrina establecida en Michaud. Desde luego, y como en Michaud, en Avotins el órgano judicial nacional (el Tribunal Supremo de Letonia) no había planteado tampoco una cuestión prejudicial ante el TJUE.

Sin embargo, el Tribunal considera que esta segunda condición no debe aplicarse con excesivo formalismo, y sin tener en cuenta las características propias del mecanismo de garantía de que se trate. En particular, no estima que sea necesario, para la aplicación de la doctrina Bosphorus, exigir en todo caso el planteamiento de la cuestión prejudicial. En el caso concreto, el Tribunal distingue la situación planteada de la existente en Michaud. El recurrente no había pedido en ningún momento al Tribunal Supremo de Letonia que planteara una cuestión prejudicial ante el TJUE; por otro lado, tampoco había propuesto en su momento ningún argumento específico sobre la interpretación de la norma europea aplicable que debiera haber provocado que el tribunal letón planteara esa cuestión. En

16 Avotins contra Letonia, de 23 de mayo de 2016 (Gran Sala). 
consecuencia, el hecho de que la cuestión no se planteara ante el TJUE no representaba un factor decisivo en el caso.

Así, y, en las circunstancias específicas del caso, el Tribunal no estimó que la protección por los mecanismos garantizadores del Derecho de la Unión de los derechos invocados fuera manifiestamente deficiente, ni que, por ello, debiera rechazarse ab initio la presunción de protección equivalente. El Tribunal procede por tanto a analizar, superadas las dos condiciones previas, si tal presunción se ve desvirtuada en el caso. Examina pues si la protección del derecho fundamental invocado (el artículo 6.1 del Convenio) otorgada por el Tribunal Supremo de Letonia en aplicación del reglamento de la Unión fue manifiestamente deficiente; tanto en cuanto al contenido del Derecho europeo aplicado como en cuanto a su aplicación en el caso. Y concluye que tal no fue el caso, por lo que la presunción Bosphorus es aplicable en cuanto al fondo ${ }^{17}$.

\section{TEDH Y CUESTIÓN PREJUDICIAL. ULLENS DE SCHOOTEN}

Un aspecto también a destacar respecto del ámbito de la jurisdicción del Tribunal de Estrasburgo, según su jurisprudencia, en relación con la actividad de la Unión Europea es el relativo a su eventual control del procedimiento del planteamiento de la cuestión prejudicial prevista en el Artículo 267 del Tratado sobre el Funcionamiento de la Unión Europea, procedimiento que aparece como pieza clave para la homogeneización de la aplicación del Derecho europeo en los países de la Unión y para la relación entre los jueces nacionales como jueces del Derecho de la Unión, y el Tribunal de Luxemburgo.

Salvo algunos antecedentes de menor importancia, es en su sentencia en el caso Ullens de Schooten ${ }^{18}$ donde el Tribunal se plantea de lleno la justiciabilidad, desde la perspectiva del artículo 6 del Convenio (derecho a un proceso equitativo) de la actuación de los tribunales nacionales en relación con el planteamiento de la cuestión prejudicial ante el Tribunal de Luxemburgo. En el caso, los recurrentes se quejaban de la negativa, por parte del Tribunal de Casación, y del Consejo de Estado belgas, del planteamiento de esa cuestión, a pesar de que sus resoluciones no eran ya susceptibles de recurso alguno interno, al agotar las vías disponibles. El Tribunal establece en forma inicial su posición en cuanto a la aplicación a estos supuestos del derecho a un proceso justo, en el sentido de derecho de acceso a la justicia.

En términos forzosamente generales, esa posición podría describirse como sigue. El artículo 6 del Convenio no reconoce un derecho a que un tribunal

17 En el texto en inglés de la sentencia, «Hence, in the specific circumstances of the present case, the Court does not consider that the protection of fundamental rights was manifestly deficient such that the presumption of equivalent protection is rebutted» $(\$ 125)$.

18 Ullens de Schootens y Rezabek contra Bélgica, de 20 de septiembre de 2011. 
plantee una cuestión prejudicial ante otra jurisdicción. Ahora bien, si ese tribunal actúa en forma arbitraria al negarse a ese planteamiento, el artículo 6 del Convenio podría verse vulnerado. Y un rechazo habría de considerarse arbitrario si careciese de algún tipo de fundamento en alguna norma. En el caso, es la normativa de la Unión la que regula el régimen de la cuestión prejudicial ante el Tribunal de Luxemburgo (Art. 267.3 TFUE) y es la jurisprudencia de este Tribunal la que a partir de la sentencia CILFIT ha fijado los tres motivos por los que cabe que un órgano jurisdiccional de ultima instancia pueda sustraerse a la obligación, impuesta por esa normativa, de plantear la cuestión. Estos motivos podrían resumirse como la falta de pertinencia de la cuestión, la existencia de una previa interpretación por parte del Tribunal de justicia o el que se trate de un «acto claro».

En otros términos, según el Tribunal de Estrasburgo, el órgano judicial al que se solicite el planteamiento de la cuestión (incluso si no se trata de un tribunal de última instancia) debe motivar su decisión de no plantearla a la luz del Derecho europeo aplicable. Debe señalarse que el Tribunal no entra a conocer de la mayor o menor adecuación de la motivación (esto es, no conoce de la corrección de la aplicación del Derecho de la Unión y de la jurisprudencia CILFIT) sino que se limita a aplicar su doctrina sobre cómo debe conducirse un proceso para que cumpla con las exigencias del artículo 6 del Convenio. En este sentido, el Tribunal ha podido señalar que considera motivación suficiente el que el órgano judicial haga referencia a alguno de los motivos de rechazo establecido en la jurisprudencia del TJUE.

Aun cuando en Ullens, el Tribunal de Estrasburgo consideró que no había habido violación del artículo 6 del Convenio ${ }^{19}$, la posición del Tribunal no dejó de suscitar una cierta polémica, por cuanto desde una perspectiva distinta, el planteamiento de la cuestión debería considerarse, no como un trámite procesal que constituyera un derecho para las partes del proceso, sino más bien como un tipo de «dialogo entre jueces» que no afectaba sustancialmente al proceso mismo; así, pudo señalarse que el planteamiento de la cuestión era independiente de la iniciativa de las partes en el proceso, pudiendo el órgano jurisdiccional plantearlo a iniciativa propia ${ }^{20}$

El Tribunal, en casos posteriores en que sí ha considerado que el rechazo de la solicitud de planteamiento ha sido arbitrario, representando por ello una

19 El Tribunal llegó también a una conclusión similar en varias decisiones posteriores (Vergauwen $c$. Belgica, de 10 de abril de 2012: Greneche y Ryon c. Francia, de 15 de octubre de 2013) lo que llevó a la inadmisión de las correspondientes demandas.

20 J. MALENOWSKy, «Le renvoi préjudiciel perçu par trois cours "souveraines" ", Journal de droit européen, n. 200 (juin 2013), pp. 414-224; F. FINES, «Le renvoi préjudiciel de l'article 267 TFUE dans le système de la Convention européenne des droits de l'homme», F. BERrod et. al, (coords.), Europe(s), droit(s)européen(s) : une passion d'universitaire : liber amicorum en l'bonneur du professeur Vlad Constantinesco, Bruylant, Bruxelles, 2015. pp. 177-192. 
violación del artículo 6 del Convenio, ha reafirmado su posición en Ullens. Así, en $D h a b b i^{21}$, el Tribunal basa su conclusión de que ha habido una vulneración de ese artículo en que en la sentencia de la Corte de casación italiana no es posible encontrar referencia alguna a la petición de planteamiento de la cuestión, ni a las razones por las que consideraba que no cabía acceder a esa solicitud. Una conclusión similar puede encontrarse en la sentencia en el caso Schipani ${ }^{22}$, debido a la falta de respuesta adecuada por parte de la Corte de Casación Italiana a la petición de planteamiento de la cuestión.

Una consideración adicional es procedente sobre esta materia. La naturaleza de la cuestión prejudicial no supone que el recurrente en un procedimiento tenga derecho a que el órgano jurisdiccional plantee en todo caso la cuestión ante el Tribunal de Justicia; el tribunal nacional podrá o deberá hacerlo (según los casos) cuando estime que hay alguna duda («si estima necesaria una decisión al respecto» según el art. 267 TFUE) sobre la interpretación de Derecho de la Unión ${ }^{23}$. No es pues extraño que la jurisprudencia del Tribunal Europeo de Derechos Humanos no exija, para apreciar el agotamiento de las vías internas disponibles, que el recurrente ante el mismo haya planteado esa cuestión; tal planteamiento no representaría un recurso efectivo ante los tribunales nacionales ante la ausencia de una obligación general por parte del juez nacional, de elevar al Tribunal de Luxemburgo la cuestión prejudicial. Por ello, la jurisprudencia del Tribunal (así en la sentencia en el caso $A k d i v a r^{24}$ ) ha insistido en que cabe presentar un recurso ante el Tribunal de Estrasburgo sin haber planteado la cuestión prejudicial.

Ahora bien, ello no significa que, a los efectos de la exigencia de agotamiento de las vías internas antes de acudir al Tribunal de Estrasburgo el planteamiento de la cuestión prejudicial sea irrelevante. Si bien ese planteamiento no resulta obligatorio, el hecho de que efectivamente se haya llevado a cabo puede tener consecuencias de importancia. Así, en un caso en que se había presentado una demanda contra Hungría ante el Tribunal de Estrasburgo ${ }^{25}$, relativa a una alegada vulneración del Artículo 1 del Protocolo 1 (derecho de propiedad) algunos de los demandantes habían presentado, con posterioridad, ante los tribunales húngaros, una demanda de compensación por responsabilidad del Estado. El tribunal nacional competente planteó una cuestión prejudicial ante el TJUE, que la resolvió estableciendo los criterios de responsabilidad del Estado, en casos de vulneración del artículo 17 de la Carta de Derechos Fundamentales, equivalente al

21 Dhabbi contra Italia, de 8 de abril de 2014

22 Schipani y otros contra Italia, de 21 de julio de 2015.

23 En términos del TJUE, «En efecto, la cuestión prejudicial reposa sobre un diálogo entre jueces, cuya iniciativa depende en su totalidad de la apreciación que el órgano jurisdiccional nacional haga sobre la pertinencia y la necesidad de dicha remisión (ver las sentencias ya citadas Kempter, punto 42, y Cartesio, punto 91)». VB Pénzügyi Lízing Zrt. contra Ferenc Schneider. C-137/08, (Gran Sala) de 9 noviembre 2010, \$29.

24 Akdivar contra Turquía, de 16 de septiembre de 1996 (Gran Sala).

25 Laurus Invest Hungary Kft y otros contra Hungría, (decisión) de 8 de septiembre de 2015. 
artículo 1 del Protocolo 1. Pues bien, antes de que el tribunal húngaro dictara su decisión a la vista de la respuesta del TJUE, el Tribunal de Estrasburgo procedió a declarar inadmisible la demanda ante él presentada, a la vista de la decisión de Luxemburgo, por no agotamiento de las vías internas. En efecto, el TEDH estimó que la resolución del Tribunal de Justicia ofrecía una perspectiva razonable de que los tribunales húngaros fallaran en el fondo del caso a favor de los demandantes, y que por esa vía podrían obtener un resarcimiento de las alegadas vulneraciones de su derecho de propiedad, sin que el Tribunal de Estrasburgo debiera pronunciarse sobre una materia situada dentro del Derecho de la Unión y sobre la que ya se había pronunciado el Tribunal de Justicia.

\section{EL ÁMBITO DE LA JURISDICCIÓN DEL TJUE. AKERBERG FRANSSON}

Un aspecto esencial a tener en cuenta para precisar las relaciones entre los Tribunales de Estrasburgo y Luxemburgo es el referente a sus distintos ámbitos de jurisdicción en lo que se refiere a la protección de derechos humanos. Si bien estos ámbitos son parcialmente coincidentes en cuanto a los derechos protegidos - por cuanto que los derechos consagrados en el Convenio Europeo de Derechos Humanos se encuentran también reconocidos en la Carta Europea de Derechos y Libertades Fundamentales - no cabe olvidar que en esta materia el Tribunal de Luxemburgo, en comparación con el de Estrasburgo se encuentra ante una evidente limitación, material y territorial. Si bien su protección se extiende a todos los derechos de la Carta, esa protección se proyectará únicamente respecto de los países integrados en la Unión Europea, y únicamente cuando se trate de cuestiones relativas a la aplicación del Derecho de la Unión. En otras palabras, el Tribunal no se configura en su esencia como un tribunal de derechos humanos, por cuanto no tiene como función la de proteger, de manera universal, los derechos reconocidos en la Carta respecto de todas las personas sometidas a la jurisdicción de los países miembros de la Unión ${ }^{26}$. Tal protección, en virtud de la misma Carta, se verá restringida a los casos en que esté involucrado el Derecho de la Unión. Según el artículo 51 de la Carta,

1. Las disposiciones de la presente Carta están dirigidas a las instituciones, órganos y organismos de la Unión, dentro del respeto del principio de subsidiariedad, así como a los Estados miembros únicamente cuando apliquen el Derecho de la Unión. Por consiguiente, éstos respetarán los derechos, observarán los principios y promoverán su aplicación, con arreglo a sus

26 Pero ver las consideraciones de Wolfgang Weiss en «The EU Human Rights Regime post Lisbon: Turning the CJEU into a Human Rights Court?», S. MORANO-FOADI et. al (eds.), Fundamental Rights in the EU. A Matter for Two Courts, Hart, Oxford, 2015, pp. 69-89. 
respectivas competencias y dentro de los limites de las competencias que los Tratados atribuyen a la Unión.

2. La presente Carta no amplía el ámbito de aplicación del Derecho de la Unión más allá de las competencias de la Unión, ni crea ninguna competencia o misión nuevas para la Unión, ni modifica las competencias y misiones definidas en los Tratados.

El Tribunal de Luxemburgo se define pues como un tribunal encargado de velar por la aplicación e interpretación del Derecho de la Unión en su conjunto, incluyendo desde luego la Carta de Derechos Fundamentales en cuanto texto vinculante, pero sin que agote ahí su función. La efectividad del Derecho de la Unión aparece así, como el mismo Tribunal se ha encargado de subrayar, como el contexto forzoso en que la actuación del Tribunal debe desarrollarse.

El problema que se plantea consiste, desde luego, en la concreción del vínculo o nexo que una materia determinada deba tener con el Derecho de la Unión para que el Tribunal de Luxemburgo considere que los derechos de la Carta son aplicables en virtud de las obligaciones de los Estados ante la Unión, y, por tanto que la protección de esos derecho cae dentro de su jurisdicción. Hay que tener en cuenta, para apreciar la extensión del problema, que el ámbito del Derecho de la Unión se hace progresivamente más extenso, y es difícil encontrar algún aspecto de la vida social y jurídica que no tenga alguna conexión con el mismo una interpretación amplia del artículo 51 de la Carta podría conducir a que el Tribunal se convirtiera en la práctica en juez universal europeo de los derechos en ella reconocidos en todo tipo de situaciones.

El Tribunal ha ido estableciendo criterios respecto del ámbito de su jurisdicción en estas materias, en una actividad aún en desarrollo. Posiblemente, su posición más clara haya sido hasta el momento la establecida en su Sentencia Akerberg Fransson ${ }^{27}: \$ 19$. «En efecto, conforme a reiterada jurisprudencia del Tribunal de Justicia, en esencia, los derechos fundamentales garantizados en el ordenamiento jurídico de la Unión deben ser aplicados en todas las situaciones reguladas por el Derecho de la Unión, pero no fuera de ellas. El Tribunal de Justicia ya ha indicado que, por este motivo, no puede apreciar a la luz de la Carta una normativa nacional que no se inscriba en el marco del Derecho de la Unión. Por el contrario, cuando una normativa nacional está comprendida en el ámbito de aplicación del Derecho de la Unión, el Tribunal de Justicia debe proporcionar, en el marco de una remisión prejudicial, todos los elementos de interpretación necesarios para que el órgano jurisdiccional nacional pueda apreciar la conformidad de dicha normativa con los derechos fundamentales cuyo cumplimiento debe garantizar».

27 C-617/10 Akerberg Fransson. Para un amplio comentario de esta sentencia, ver S. IGLESIAS SÁNCHEZ, «Tribunal de Justicia de la Unión Europea-TJUE-Sentencia de 26.2.2013 (Gran Sala) — Aklagaren y Hans Akerberg Fransson, asunto C-617/10 «Carta de los derechos fundamentales de la Unión Europea-Ámbito de aplicación - Artículo 51-Aplicación del Derecho de la Unión - Artículo 50-Principio non bis in ídem. La confirmación del ámbito de aplicación de la Carta y su interrelación con el estándar de protección». RDCE, 46, 2013, pp. 1157-1175. 
La jurisdicción del Tribunal de Luxemburgo, en consecuencia, se extiende a la protección de los derechos fundamentales de la Carta en cuanto insertos en una materia regida por el Derecho de la Unión: en el caso, el impuesto sobre el valor añadido y, como conexión forzosa, las sanciones derivadas de la evasión fiscal. Ese régimen se encuentra regulado por la Directiva 2006/112 EC de 28 de noviembre de 2006, y, como es sabido, parte de los fondos de la Unión derivan de los ingresos percibidos por los Estados en virtud de ese impuesto.

Akerberg Fransson proporciona unos criterios generales que han debido ser precisados en decisiones posteriores, en un proceso aún abierto. Frente a posibles interpretaciones extensivas, el Tribunal ha podido señalar, por ejemplo, que la jurisdicción del Tribunal en materia de derechos fundamentales será invocable únicamente cuando la materia de que se trate pueda considerarse en el ámbito del Derecho de la Unión Europea sólo si los mandatos de ese Derecho imponen obligaciones concretas a los Estados Miembros, sin que pueda invocarse una conexión indirecta ${ }^{28}$.

\section{EL DIÁLOGO ENTRE TRIBUNALES}

La coexistencia de dos sistemas de protección internacional de derechos fundamentales, y la presencia en sus respectivas cúspides de dos tribunales competentes sobre esta materia ha conducido, en virtud del «movimiento forzoso de las cosas» de que se ha hecho mención más arriba, al establecimiento de un diálogo entre ambos Tribunales, primeramente en la forma genérica de mutuas referencias, y posteriormente y como se verá, en un proceso de interacción aún por desarrollarse en profundidad. Especialmente, la entrada en vigor con carácter vinculante de la Carta de Derechos Fundamentales de la Unión en virtud del Tratado de Lisboa ha supuesto un punto de inflexión, en ambos aspectos, en la práctica de los dos Tribunales ${ }^{29}$.

Por lo que atañe al Tribunal de Luxemburgo, hasta esa entrada en vigor, el Convenio Europeo representaba (junto a las «tradiciones constitucionales comunes») un punto de referencia prioritario, a la hora de precisar los derechos fundamentales derivados de los «principios generales» del Derecho de la Unión; en algún caso bien conocido, el Tribunal reformó sus líneas jurisprudenciales para

28 Ver sobre esta materia el artículo de J. Кокотт у C. Sовотта, «Protection of Fundamental Rights in the European Union: on the relationship between EU fundamental rights, the European Convention and national standards of protection», Yearbook of European Law, 34(2015) pp. 60-73. Como ejemplos de la evolución de la doctrina del Tribunal de Luxemburgo en esta materia, los autores citan, como ejemplo, las decisiones en los casos C 117/14 Nisstabuz Poclava;C-206/13 Siragusa, y C-282/14 Styilinart.

29 Ver sobre este punto, por ejemplo, D.l EnGEL, Der Beitritt der Europäische Union zur EMKR, cit., pp. 33-35. Tambien, WEIss, «The EU Human Rights Regime...» cit. 
adecuarlas a las directrices de Estrasburgo ${ }^{30}$. La proclamación de la Carta de Derechos en 2000 no varió esta situación, dada su inicial falta de carácter vinculante.

La aprobación del Tratado de Lisboa, y la asunción por la Carta de ese carácter supusieron una cierta alteración de la línea seguida por el Tribunal de Luxemburgo, en el sentido de que los derechos proclamados por la Carta en cuanto Derecho de la Unión adquirieron una posición prioritaria en la jurisprudencia del Tribunal. Ello no significa desde luego, como ha podido notarse, que la doctrina de Estrasburgo haya dejado de ser relevante en la práctica del TJUE; de hecho éste hace continua referencia a las Sentencias del TEDH, y no deja de ser significativo que su jurisprudencia sea expresamente citada en las sentencias de Luxemburgo. Pero la nueva situación de la Carta ha llevado a que el TJUE practique una interpretación «autónoma» de sus preceptos, y que la cita del Convenio y de la jurisprudencia de Estrasburgo se realice, por la vía del artículo 52.1.3 de la Carta ${ }^{31}$, no como la ratio decidendi de las resoluciones del TJUE, sino como «fuente de conocimiento jurídico» en esas resoluciones ${ }^{32}$.

\section{EL TEDH Y LA JURISPRUDENCIA DEL TRIBUNAL DE JUSTICIA. A Y B CONTRA NORUEGA, TARAKHEL, $X$ CONTRA LETONIA}

En cuanto al TEDH, este Tribunal parte en su jurisprudencia, por un lado, de la constatación de que no es su misión sustituir al TJUE como Tribunal del Derecho de la Unión, y por otro, de que la jurisprudencia de ese Tribunal representa una aportación relevante a la hora de determinar el contenido de derechos reconocidos tanto en el Convenio Europeo de Derechos Humanos como en el Derecho de la Unión.

En cuanto al primer aspecto, y desde una posición si se quiere «negativa» el Tribunal de Estrasburgo conscientemente se abstiene de sustituir al TJUE en su función de interpretación de la legislación europea. Así, en la sentencia en el caso A.T. contra Luxemburgo ${ }^{33}$, de 9 de abril de 2015, relativa a la garantía de las personas detenidas en virtud de un mandato europeo de detención y entrega, el Tribunal consideró que no le correspondía decidir sobre la interpretación de la

30 Por ejemplo, en Roquette Frères, C-94/00, de 22 de octubre de 2002.

31 52.1.3. En la medida en que la presente Carta contenga derechos que correspondan a derechos garantizados por el Convenio Europeo para la Protección de los Derechos Humanos y de las Libertades Fundamentales, su sentido y alcance serán iguales a los que les confiere dicho Convenio. Esta disposición no obstará a que el Derecho de la Unión conceda una protección más extensa.

32 ENGEL, cit., p. 35. Ver también, sobre esta cuestión, las consideraciones de C. RAUCHEGgER y Sarah LAmbrecht en «European Union: the EU's Attitude to the ECHR» en P. Popelier et. al. (dirs.), Criticism of the European Court of Human Rights. Shifting the Convention System: Counterdynamics at the National and EU Level. Intersentia, Cambridge, 2016, 41-72, esp. pp. 49-55.

33 A.T. contra Luxemburgo, de 9 de abril de 2015. 
directiva 2013/48 en el sentido de deducir de ella un derecho de la defensa a tener acceso a las actuaciones policiales antes del primer interrogatorio del detenido ante el juez de instrucción. El Tribunal se limita a examinar los derechos de defensa del recurrente desde la perspectiva del Convenio, para concluir que no garantiza el derecho ilimitado al acceso al dossier policial antes del primer interrogatorio.

En cuanto a lo segundo, ha de señalarse que, desde muy tempranamente, el Tribunal se ha referido a la jurisprudencia del Tribunal de Luxemburgo para fundamentar o reforzar su interpretación del Convenio y sus protocolos y los derechos allí reconocidos. Podría además apreciarse que este tipo de referencias ha ido aumentando según el Tribunal de Luxemburgo iba reforzando su papel de garante de los derechos fundamentales en el ámbito del Derecho de la Unión. Como ha podido señalar algún autor, el Tribunal, inicialmente, hizo mención de la jurisprudencia de Luxemburgo en forma muy medida, para ir incrementando progresivamente este tipo de referencias ${ }^{34}$. Y, a partir de la entrada en vigor del Tratado de Lisboa, y cobrar la Carta de Derechos Fundamentales de la Unión carácter vinculante, las referencias a la jurisprudencia de Luxemburgo, incluso en forma de diálogo explícito, se han hecho frecuentes. Valga señalar varios ejemplos de este diálogo entre Tribunales.

En su sentencia en el caso $A$ y $B$ contra Noruega ${ }^{35}$, el Tribunal toma en cuenta la posición del Tribunal de Luxemburgo en el caso Akerberg Fransson, citado, sobre la concurrencia de sanciones penales y administrativas en materia fiscal, para precisar su jurisprudencia anterior. En su sentencia en el caso Zolokbutin ${ }^{36}$, el Tribunal había encontrado una violación de la prohibición de doble incriminación del artículo 4 del Protocolo 7, aplicando, para la definición de las sanciones impuestas (es decir sobre su carácter penal o administrativo) los criterios sentados en su sentencia en el caso Engel $^{37}$. Si una doble sanción de tipo penal se imponía por los mismos hechos (independientemente de la definición de esa sanción en Derecho interno) debía apreciarse que se había producido una violación del artículo citado.

En el caso Ackerberg Fransson, dictado en una cuestión preliminar, el Tribunal de Justicia, aún sin pronunciarse sobre el fondo del asunto, al remitir la decisión sobre doble incriminación a los tribunales nacionales, vino, en forma indirecta, a referirse a la presencia de factores que debían tenerse en cuenta a la

34 Para la fase anterior al Tratado de Lisboa, S. Douglass-ScotT, «A Tale of Two Courts: Luxembourg Strasbourg and the growing European Human Rights Acquis», Common Market Law Review 43 (2006), pp. 629 y ss. Para la fase posterior, de la misma autora, «The Court of Justice of the European Union and the European Court of Human Rights after Lisbon», DE VRIES, S. et al. (eds.), Protection of Fundamental Rights in the EU after Lisbon, Hart Publishing, Oxford, 2013, pp. 153 y ss.

35 A y B contra Noruega, de 15 de noviembre de 2016 (Gran Sala).

36 Sergey Zolokbutin contra Rusia, de 10 de febrero de 2009 (Gran Sala).

37 Engel y otros contra Países Bajos, de 8 de junio de 1976. 
hora de pronunciarse sobre una posible doble incriminación, y que (aún empleando los criterios de la jurisprudencia Engel del TEDH) podían interpretarse como una llamada de atención al Tribunal de Estrasburgo ${ }^{38}$. Y éste no dejó de tener en cuenta la opinión del TJUE. En la sentencia $A$ y $B$ contra Noruega, el Tribunal Europeo llevó a cabo una precisión de su posición sobre la existencia de doble incriminación, con la peculiaridad de citar expresamente la opinión del Abogado General (Cruz Villalón) en el caso Ackerberg Fransson:

El Tribunal toma nota de la observación formulada por el Abogado General ante el Tribunal de Justicia de la Unión Europea en el caso Fransson (...) concretamente que la imposición de sanciones penales y en relación con la misma infracción es una práctica extendida en los Estados miembros de la Unión, especialmente en áreas como impuestos, politicas sobre el medio ambiente y seguridad pública. El Abogado General también indicó que la forma en que se acumulan esas sanciones varía enormemente entre los diversos sistemas, y muestra peculiaridades específicas en cada Estado miembro; en la mayoría de los casos, esas particularidades se adoptan para moderar los efectos de la imposición de dos sanciones por la autoridad pública» (\$118).

El Tribunal (en parte como resultado de su toma en consideración de Fransson) especifica que «en casos afectando al artículo 4 del protocolo 7, la tarea del tribunal consiste en determinar si la especifica medida nacional impugnada implica, en sustancia o como efecto, una doble incriminación en detrimento del individuo, o si, por el contrario, es el resultado de un sistema integrado que hace posible el tratamiento de de distintos aspectos del ilícito en forma previsible y razonable, formando un todo coberente, de forma que el individuo afectado no sea sometido a un tratamiento injusto» $(\$ 122)^{39}$.

Una de las cuestiones en que ambos tribunales, de Estrasburgo y Luxemburgo, ostentan jurisdicción es la referente a la entrada y permanencia de inmigrantes en los Estados de la Unión Europea, y más concretamente, al régimen de las solicitudes de asilo, a la vista de los derechos reconocidos en el Convenio y la Carta Europea. Ello se ha hecho evidente en varios casos referentes a la aplicación de las llamadas Reglas de Dublín, (en sus sucesivas versiones) sobre las obligaciones de los Estados que las suscriben relativas al envío, para una decisión sobre esa solicitud, del demandante de asilo al país en que hubiera efectuado su primera entrada en el ámbito territorial de la Unión Europea. La cuestión se ha planteado respecto de si el país obligado a tal envío, y donde se encuentra el solicitante, puede vulnerar derechos reconocidos en el Convenio Europeo si expone al demandante a peligros para su integridad física y moral si lleva a cabo ese envío: bien por las condiciones en que se encontraría en el país de destino, bien por el peligro

38 ENGEL, Der Beitritt... cit., p. 39.

39 Una referencia a Akerberg Fransson puede encontrarse también en la Sentencia del TEDH en el caso Grande Stevens v. Italia (de 4 de marzo de 2016) para reiterar que un Estado no puede imponer una doble sanción (administrativa y penal) por los mismos hechos más que si la primera sanción no reviste carácter penal (\$34). 
de que fuera expulsado sin las debidas garantías del ámbito de la Unión, viéndose expuesto a graves peligros en su país de origen.

El Tribunal de Estrasburgo ha ido exponiendo una serie de consideraciones sobre este tema, sobre todo en las Sentencias en los casos MSS $S^{40}$, y Tarakbel ${ }^{41}$. Con anterioridad había tenido ya la oportunidad de establecer varios principios a tener en cuenta en relación con las reglas de Dublín. Así, en su decisión T.I contra Reino Unido ${ }^{42}$, vino a señalar que el hecho de que un Estado firmante del Convenio hubiera ratificado un acuerdo internacional sobre el régimen de concesión de asilo no le exoneraba de sus responsabilidades en materia del cumplimiento de sus obligaciones derivadas del Convenio en este respecto, y que no podía, sin más, trasladar al conjunto de países firmantes del acuerdo esas responsabilidades. Aún así, en ese caso (así como en su decisión KRS c. Reino Unido $0^{43}$ ) declaró inadmisible la demanda presentada, por considerar que el sistema Dublín protegía suficientemente los derechos del Convenio (arts. 2 y 3) tanto en lo que se refería a las garantías sustantivas que ofrece como respecto de los mecanismos previstos para controlar la aplicación de esas garantías.

Aun así, y en un caso posterior, en su sentencia MSS contra Grecia y Bélgica, el Tribunal se pronunció en el sentido de encontrar una vulneración de derechos del Convenio, no sólo por las condiciones de los solicitantes de asilo en Grecia, sino también por la aplicación por Bélgica de las reglas de Dublín, sin que cupiera aplicar al caso la presunción Bosphorus. Habida cuenta de la penosa situación de los solicitantes de asilo en Grecia, el Tribunal condenó a este país por violación de los artículos 3 y 13 del Convenio. Pero además, condenó a Bélgica (sin aplicar la presunción Bosphorus, dada la presencia de un amplio margen de discrecionalidad en la ejecución de las reglas de Dublín) dado que las autoridades belgas no se informaron adecuadamente de las formas en que las autoridades griegas aplicaban en la practica esas reglas, y sin tener en cuenta que los malos tratos invocados por el recurrente (demandante de asilo) eran suficientemente reales e individualizados como para hacer entrar en juego el artículo 3 del Convenio.

Hay que señalar que esta jurisprudencia se ha visto reflejada en varias resoluciones del Tribunal de Justicia de la Unión, referentes también a la compatibilidad de los derechos fundamentales (esta vez de la Carta) a no ser sometido a tratos inhumanos o degradantes como consecuencia de la expulsión, en virtud de las reglas de Dublín al país de entrada en la Unión Europea por el país donde se encontrara el solicitante de asilo. Ahora bien, las resoluciones del Tribunal de Justicia hacen referencia a un aspecto del que no hacía expresamente mención la sentencia MSS. En palabras del TJUE, «para que la Unión y sus Estados miembros

40 MSS contra Bélgica y Grecia, de 21 de enero de 2011 (Gran Sala).

41 Tarakhel contra Suiza, de 4 de noviembre de 2014 (Gran Sala).

42 De 7 de marzo de 2000.

43 De 2 de diciembre de 2008. 
puedan respetar sus obligaciones relativas a la protección de los derechos fundamentales de los solicitantes de asilo, incumbe a los Estados miembros, incluidos los órganos jurisdiccionales nacionales, no trasladar a un solicitante de asilo al «Estado miembro responsable» en el sentido del Reglamento n. ${ }^{\circ}$ 343/2003 cuando no puedan ignorar que las deficiencias sistemáticas ${ }^{44}$ del procedimiento de asilo y de las condiciones de acogida de los solicitantes de asilo en ese Estado miembro constituyen motivos serios y acreditados para creer que el solicitante correrá un riesgo real de ser sometido a tratos inhumanos o degradantes en el sentido del artículo 4 de la Carta» ${ }^{45}$.

En esa misma línea, invocando las «deficiencias sistémicas» como causa de incompatibilidad con la prohibición de tratos inhumanos y degradantes del artículo 4 de la Carta (y del artículo 3 del Convenio) se pronunció la sentencia en el caso Abdullabit6 de 10 de diciembre de 2013.

Esta referencia a la presencia de «deficiencias sistémicas» «cobra relevancia en cuanto implica una excepción al principio de mutua confianza que debe regir entre los países miembros de la Unión. Valga recordar que, por ejemplo, en su famosa Opinión 2/13, el Tribunal de Justicia, sobre la adhesión de la Unión al Convenio Europeo de Derechos Humanos, recordaba que el principio de confianza mutua exige que todos los miembros de la Unión deben considerar que los demás Estados miembros cumplen con el Derecho de la Unión en lo que se refiere a los derechos fundamentales, salvo que aprecien circunstancias excepcionales. De acuerdo con Abdullabi, cabría excluir esa presunción, en casos de aplicación de las reglas de Dublín, si tales circunstancias excepcionales se dieran en el país de destino.

El Tribunal de Estrasburgo ha venido, en su sentencia Tarakhel contra Suiza, a completar las líneas expresadas en MSS, dando entrada también a consideraciones «sistémicas». El Tribunal indica que, en el caso de Suiza, para verificar si se ha respetado el mandato del artículo 3 del Convenio, en el supuesto de expulsión de un solicitante de asilo a Italia, las autoridades suizas debían determinar «si, a la vista de la situación general del dispositivo de acogida de los solicitantes de asilo en Italia, y de la situación particular de los recurrentes, existían motivos serios y comprobados para creer que en caso de ser expulsados a Italia, los recurrentes correrían el riesgo de sufrir tratamientos contrarios al artículo $3 »$. Viene así a unir la consideración de la «situación general» (equivalente a las deficiencias sistémicas apreciadas por el TJUE) a las referentes a la situación particular de los recurrentes. Valga señalar que las sentencias del TJUE en los casos NS y Abdullabi no hacen referencia expresa a esa situación particular de riesgo; pero, por un lado, no la excluyen, y por otro, y en el caso de Grecia, su apreciación no era necesaria, al haberse estimado por el

44 El texto en español emplea el término «sistemáticas»; los textos en francés e inglés, respectivamente, los términos «systématiques» y systemic». En adelante, se utilizará en estas líneas el término «sistémicas» que parece más adecuado.

45 Sentencia NS y otros, C-411/10, de 21 de diciembre de 2011, \$94.

46 Abdullabi, C-394/12, de 10 de diciembre de 2013. 
TJUE la presencia de una situación general de deficiencia sistémica incompatible con el artículo 4 de la Carta ${ }^{47}$.

Una materia en que el diálogo - explícito o implícito- entre los Tribunales de Estrasburgo y Luxemburgo resulta especialmente relevante para la garantía de los derechos reconocidos tanto en el Convenio como en la Carta referentes a la vida familiar (arts. 8 y 7 , respectivamente) es la que versa sobre los aspectos civiles de los secuestros internacionales de menores. La evolución de la jurisprudencia de ambos Tribunales va creando en forma progresiva un elenco común de principios a partir tanto de los mandatos citados, como de la Convención de La Haya de 25 de octubre de 1980, y para el ámbito de la Unión Europea, del Reglamento CE 2201/2003 de 27 de noviembre de 2003. El punto clave de los contenciosos sobre el tema suele ser la excepción contenida en el artículo 13.1. b) de la Convención al principio de devolución inmediata del menor sustraído a su país de origen o residencia habitual, es decir la referente al peligro de que esa devolución cause al menor un daño físico o psíquico. El Reglamento de Bruselas II bis representa un desarrollo restrictivo de esta cláusula, que permite superar esa excepción mediante una decisión (certificación) del juez del país de origen.

La interpretación de esta normativa en su conjunto ha dado lugar a diversos casos ante las jurisdicciones de Estrasburgo y Luxemburgo, centradas sobre el derecho a la vida familiar y a la defensa del interés superior del menor. En estos casos, la principal cuestión debatida es usualmente el papel respectivo de los órganos judiciales del país de residencia y del país al que el menor ha sido sustraído. El sistema de La Haya (y del Reglamento Bruselas II bis) confiere un papel determinante al juez del país de origen: la evolución de la jurisprudencia del Tribunal Europeo de Derechos Humanos ha ido precisando ese papel a la luz del Convenio, en busca de una concordancia práctica con la jurisprudencia del TJUE ${ }^{48}$.

Hasta el momento, la línea orientadora de la jurisprudencia del Tribunal de Estrasburgo puede encontrarse sobre todo en su sentencia en el caso $X$ contra

47 Un tema similar se plantea respecto de la ejecución de la Orden Europea de Detención y Entrega cuando existe peligro de malos tratos en el país de destino. Por ejemplo, en Aranyosi, (Pál Aranyosi, C-404/15 y Robert Căldăraru C-659/15, de 5 de abril de 2016). el Tribunal de Justicia, después de afirmar que « de la jurisprudencia del TEDH se desprende que el artículo 3 del CEDH impone a las autoridades del Estado en cuyo territorio se lleve a cabo un encarcelamiento la obligación positiva de cerciorarse de que cualquier reo esté recluido en condiciones que garanticen el respeto de la dignidad humana, de que las modalidades de ejecución de la medida de privación de libertad no expongan al recluso a una angustia o a dificultades cuya intensidad supere el nivel inevitable de sufrimiento inherente a la reclusión, y de que, dadas las limitaciones prácticas del encarcelamiento, se vele adecuadamente por la salud y el bienestar del recluso» (\$90) establece que «la mera existencia de elementos que acrediten deficiencias sistémicas o generalizadas que afecten a ciertos grupos de personas o a ciertos centros de reclusión en lo referente a las condiciones de reclusión en el Estado miembro emisor no implica necesariamente que, en un caso concreto, la persona de que se trate vaya a sufrir un trato inbumano o degradante en el supuesto de que sea entregada a las autoridades de ese Estado miembro» (\$93). Viene así a introducirse de nuevo un matiz «sistémico» que implica una matización de la jurisprudencia de Estrasburgo.

48 Para un detenido análisis del tema y de las relaciones entre las jurisprudencias del TEDH y el TJUE, D. PorCheron, «La jurisprudence des deux Cours européennes (CEDH et CJUE) sur le déplacement illicite d'enfant: vers une relation de complémentarité?», en Journal de Droit International 3(2015), pp. 821-844. 
Letoni $^{49}$. Pero su comprensión exige una consideración de la sentencia anterior en el caso Neulinger ${ }^{50}$.

En Neulinger, el Tribunal examinó la compatibilidad con el derecho a la vida familiar del artículo 8 del Convenio de una orden de los tribunales suizos ordenando la devolución de un menor de Suiza a Israel, en aplicación de los mandatos de la Convención de La Haya. La Gran Sala del Tribunal (revocando una sentencia anterior de una Sala) determinó que la aplicación de la Convención de la Haya por las autoridades suizas, ordenando la devolución del menor a su país de origen, sin haber llevado a cabo un examen de fondo de las circunstancias relativas al interés superior de menor representaba una violación del derecho a la vida familiar del artículo 8 del Convenio. En el caso, por lo tanto, el Tribunal concedió preferencia a los mandatos sustantivos del artículo 8 del Convenio, frente a los mandatos, básicamente procedimentales, de la Convención de La Haya, que establecen que el menor debe ser devuelto a su país de residencia, quedando los aspectos materiales relativos al interés superior del menor para su resolución por la autoridad judicial de ese país.

Este enfoque no dejó de dar lugar a un número de críticas, relativas tanto a su compatibilidad con los criterios de la Convención de La Haya como con el Reglamento Bruselas II bis, y con la misma jurisprudencia del Tribunal de Luxemburgo $^{51}$. En efecto, esta jurisprudencia toma como punto de partida el principio de confianza mutua entre los Estados de la Unión, a efecto de la creación de un espacio judicial europeo: por ello, el Tribunal de Luxemburgo estima que de acuerdo con el Reglamento Bruselas II bis, el centro de gravedad en el procedimiento debe residir en las autoridades del país de residencia, que deberán ser las que decidan sobre los aspectos sustantivos relativos al interés superior del menor y al atribución de su custodia. El papel del juez del país de sustracción debe verse muy restringido, y centrarse en la rápida ejecución de la devolución del menor demandada por el juez del país de origen, dejando para los órganos judiciales de este país la decisión sobre el fondo, esto es, sobre a quién y en qué circunstancias debe encomendarse la custodia del menor. Por ello, las objeciones del país de sustracción deben ceder en su caso ante la oportuna certificación del juez del país de origen, confirmando el mandato de devolución ${ }^{52}$.

La sentencia de la Gran Sala del Tribunal de Estrasburgo en el caso X contra Letonia tiene en cuenta estas circunstancias y viene a suponer una precisión de los principios establecidos en Neulinger.

49 X contra Letonia, de 26 de noviembre de 2013 (Gran Sala).

50 Neulinger y Shuruk contra Suiza, de 6 de julio de 2010 (Gran Sala).

51 Ver sobre el tema, Jos Silvis, «Prevention of Child Abduction: Return to the State of Origin» en J. Casadevall et. al, (eds.), Mélanges en honneur de Dean Spielmann, Wolf, Oisterwijk, 2015, pp. 603-614.

52 Ver por ejemplo, las sentencias del TJUE en Povse, C-11/10 de 1 de julio 2010, y Zárraga, C-491/10, de 22 de diciembre. 
El aparente conflicto entre los mandatos de la Convención de La Haya (y del Reglamento Bruselas II bis) y el artículo 8 del Convenio en su previa interpretación en Neulinger fue tomado en cuenta por el Tribunal en $X$ contra Letonia. En este caso, de nuevo, el recurrente se quejaba de una orden dictada por las autoridades del país a que el menor había sido sustraído (Letonia) obligando a la devolución del niño a su país de origen (Australia), en aplicación de la Convención de La Haya. El Tribunal resolvió las críticas formuladas frente a su previa sentencia en Neulinger, en la interpretación según la cual las autoridades del país de residencia actual (es decir, de aquel al que había sido secuestrado) deberían llevar a cabo un examen detallado de fondo de cual sería el interés del menor. Un aspecto de esa crítica consistía en que ese examen implicaría un notable retraso de los procedimientos para una devolución rápida establecidos por la Convención de La Haya; y, como resultado haría inefectivos tales mandatos. A la vista de estas críticas, la posición del Tribunal en $X$ contra Letonia fue una clarificación de su sentencia Neulinger. El Tribunal señaló que tal sentencia no representaba una directiva para los tribunales nacionales en el sentido de instruirles sobre cómo aplicar la Convención de La Haya, sino que esos tribunales deberían tener en cuenta las alegaciones «admisibles» (arguable) relativas a la posibilidad de que se produjera un riesgo grave para el menor en caso de devolución a su país de origen, y que, en consecuencia, los tribunales deberían ofrecer una respuesta razonable a tales alegaciones ${ }^{53}$. El Tribunal, por lo tanto, vino a imponer a esos tribunales una obligación de tipo procedimental, más que de carácter sustantivo, a la hora de aplicar la Convención de La Haya.

Y en decisiones posteriores el Tribunal de Estrasburgo ha insistido sobre la obligación que pesa sobre los Estados a los que el menor ha sido sustraído de llevar a cabo con prontitud los trámites relativos a su devolución al país de origen ${ }^{54}$.

A esta posición inicial (que supone imponer al juez del país de sustracción determinadas obligaciones procedimentales) deben añadirse las consideraciones afectando específicamente a los países de la Unión Europea sometidos al Reglamento Bruselas II bis, en relación con la aplicación de ese Reglamento. Por lo que atañe a las obligaciones de las jurisdicciones del país de origen que pide la devolución del menor, el Tribunal, en Sneersone y Kamparella c. Italia ${ }^{55}$ indicó que a la

53 En los términos de la sentencia, $(\$ 106)$ «El Tribunal considera que puede llegarse a una interpretación armónica del Convenio Europeo y de la Convención de La Haya (...) si se cumplen las dos condiciones. Primeramente, los factores que puedan constituir una excepción a la devolución inmediata del menor, en aplicación de los artículos 12, 13 y 14 de la Convención de La Haya, particularmente cuando se suscitan por una de las partes en el procedimiento, deben ser tenidos adecuadamente en cuenta por el tribunal competente. Y ese tribunal debe entonces adoptar una decisión suficientemente motivada en este aspecto, para que el Tribunal pueda verificar que tales cuestiones se han examinado efectivamente. En segundo lugar, tales factores deben evaluarse a la luz del artículo 8 del Convenio».

54 Así, Phostira Efthymiou y Ribeiro Fernándes c. Portugal, de 5 de febrero de 2015; Cavani c. Hungría, de 28 de octubre de 2014.

55 De 12 de julio de 2011. 
hora de emitir las ordenes certificadas de devolución previstas en el Reglamento Bruselas II bis, los órganos jurisdiccionales debía motivar suficientemente su decisión, y garantizar la adecuada protección del menor. En forma más radical, y respecto de las autoridades del país de sustracción, el Tribunal ha afirmado que la presunción Bosphorus es también aplicable a los supuestos de sustracción de menores entre los países de la Unión. En su decisión Povse contra Austria ${ }^{56}$, el Tribunal vino a rechazar por inadmisible una demanda frente a la orden de devolución de un menor de Austria a Italia, aplicando tal presunción. El Tribunal señaló que por una parte el juez austriaco no disponía de ningún margen de maniobra frente a la orden de devolución procedente del juez italiano, a la luz del Reglamento Bruselas II bis. Por otro lado, señaló que los derechos de la parte recurrente se encontraban suficientemente protegidos por los mecanismos de garantía previstos en el ordenamiento de la Unión, por cuanto, aun cuando el Tribunal de Justicia de la Unión no se había pronunciado en el caso concretamente sobre su aspecto material o sustantivo (es decir, a quién correspondía la custodia del menor) pues su resolución había versado sobre la competencia del juez italiano, las circunstancias sustantivas del caso deberían ser apreciadas para su decisión final por los jueces del país de residencia (es decir, Italia) que ofrecería así un mecanismo suficiente de protección a los derechos del recurrente.

Finalmente, el Tribunal de Estrasburgo ha venido a señalar las diversas perspectivas de que parten ambos tribunales a la hora de precisar el contenido y los límites de los derechos reconocidos en ambos sistemas por el Convenio y la Carta. Por ejemplo, en la sentencia en el caso Kudrevicius ${ }^{57}$ relativo a los límites del derecho de reunión y manifestación, el Tribunal se refiere a la Sentencia Schmidberger ${ }^{58}$ del TJUE, invocada por el Gobierno recurrido, para señalar que su función reside en velar por el respeto a los derechos del Convenio, quedando fuera de su competencia la apreciación y delimitación de las obligaciones derivadas del Derecho de la Unión (en el caso la libre circulación de mercancías) que podrían afectar el ejercicio de tales derechos, y cuya existencia y efectos deben ser determinados a partir del Derecho europeo, interpretado por el TJUE.

$$
* * *
$$

TITLE: The European Court of Human Rights, the Court of Justice of the European Union and "le mouvement nécessaire des choses"

ABSTRACT: The progressive development of two systems of international protection of Human Rights in Europe, one derived from the European Convention on Human Rights and the other from the Charter of Fundamental Rights of the European Union, requires coordination, particularly between the two main jurisdictional bodies of those systems, the Strasbourg and Luxembourg Courts. This article asserts that in spite of the

56 De 18 de junio de 2013.

57 Kudrevicius c. Lituania, de 15 de octubre de 2015 (Gran Sala).

58 Schmidberger, C-112/00, de 12 de junio de 2003. 
lack of formal mechanisms of coordination due to the EU's non-accession (for the time being) to the Convention, coordination is nevertheless achieved through a practical concordance between the case law of both courts, which in a process of both formal and informal dialogue is defining the scope of the two Courts' respective jurisdictions.

Resumen: El progresivo desarrollo de dos sistemas de protección internacional de derechos bumanos en Europa, a partir del Convenio Europeo de Derechos Humanos de y de la Carta de Derechos Fundamentales de la Unión Europea, hace necesaria una coordinación entre ellos, y particularmente entre los órganos jurisdiccionales en la cima de cada sistema, es decir, los Tribunales de Estrasburgo y Luxemburgo. En el presente artículo se mantiene que, pese a la ausencia de mecanismos formales de coordinación, debido a la no adhesión, hasta el momento, de la Unión Europea al Convenio, esa coordinación se está produciendo mediante una concordancia práctica entre la jurisprudencia de ambos tribunales, que, en un proceso de diálogo formal e informal, van delimitando sus respectivos ámbitos de jurisdicción.

KEY wORDS: European Court of Human Rights, Court of Justice of the European Union, International Abduction of minors, Dublin Rules, Bosphorus case.

Palabras clave: Tribunal Europeo de Derechos Humanos, Tribunal de Justicia de la Unión Europea, Sustracción internacional de menores, Reglas de Dublín, Caso Bosphorus.

FECHA DE RECEPCIÓN: 15.12.2016

FECHA DE ACEPTACIÓN: 01.02.2017 